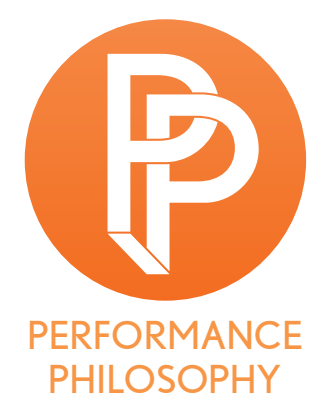

\title{
THE OPEN FIELD OF PERFORMANCE PHILOSOPHY
}

\author{
WILLDADDARIO INDEPENDENT SCHOLAR
}

Edition 4.2 of the Performance Philosophy journal is the culmination of an open call for proposals. This leads to the question: what is "open"?

On the most basic level, an "open issue" is an issue without a pre-defined topic that would actively shape the contributions' contents. But this typical meaning doesn't quite work here since the "topic" of the journal-if we spy in that word the Ancient Greek topos, or place-is the field of Performance Philosophy itself. Performance Philosophy is the place of the journal, and thus all articles, regardless of the edition's theme will convene there. Given that the definition of "Performance Philosophy"-what it is, what it does, how it acts, and how it intervenes-has yet (thankfully) to be neatly sorted out, the tacit topic of edition 4.2 is, to be more specific, a relatively open field. In this sense, edition 4.2 of the journal is an expression of the diversity of thought that populates this open field. Two of the essays included here-Brian Schultis's "Life, Movement, and Thought: Directions for Performance Philosophy and Practice as Research" and James Corby's "Failing to Think: The Promise of Performance Philosophy"-specifically address the geography and stratigraphy of this open field as well as the vectors of the various practitioners who gather there.

One take-away realization from those articles is that Performance Philosophy is still very much an open question. What are its distinguishing features? When its discourse makes claims about the thinking enacted by performance, what precisely is the nature of this thinking, and is this nature commensurate with traditional philosophical thought? In what ways is it possible for artists to take up or elaborate upon philosophers' ideas without capitulating to the language games utilized by philosophical discourse? Annette Arlander's essay, "Resting with Pines in Nida - attempts at performing with plants," picks up a version of this latter question by juxtaposing her own artistic 
research with challenges posed by Michael Marder in the inaugural edition of this journal. The result is not an answer to Marder-who wonders what a performance would look like if it could spread out in all directions like a growing plant-but a detailed open question that manages to entangle with Marder's philosophy instead of responding to it.

Erin Brannigan's essay, "Talking Back: What Dance might make of Badiou's philosophical project," albeit in a different register than Arlander's piece, also brushes up against the warren of open questions that thrive under the field of Performance Philosophy. Whereas Arlander's artistic research eschews philosophical determinations and argument for an exploratory foray into the world of plants, Brannigan steps into the role of Philosopher in order to speak back to one of the most visible and widely-read contemporary French thinkers. By taking Badiou's essay "Dance as Metaphor for Thought" seriously and "on its own terms," Brannigan postpones the typical critique of Badiou (i.e., the claim that he necessarily subjugates dance to philosophy and upholds the tired hierarchy of thought so familiar within Badiou's discipline) in order to imagine how Dance might respond to Badiou's argument. To perform this feat, Brannigan gets creative; she conjures an aesthetic persona for Dance who can draw on the discourse of dance theory and philosophy in order to enter into dialogue with Badiou. Fascinatingly, this exercise ends up disarming Badiou's certainties with a series of open questions that remain for dance theorists and practitioners despite Badiou's philosophical system, thereby turning his definite claims into possibilities, nothing more and nothing less.

In a sense, then, the call for contributions that led to edition 4.2 was a signpost that marked the location of the open field we call Performance Philosophy and invited scholars and practitioners to tarry with the open questions that have sprouted in that field over the last six years. Once gathered together, the collection of contributors reveals a third understanding of "open," one that speaks to the multiple points of entrance through which members of various disciplines can access our open field. The field is open to many. That is to say, Performance Philosophy reveals itself in this edition of the journal to have an extraordinarily diverse roster of people who claim to have something to say about the practice of performance philosophy. Genevieve Hyacinthe enters the field through the discourses of visual art and Black Atlantic studies. Her article, "The Shape of Humidity: Performing Black Atlantic Theory Making," commences from bell hooks's assertion that theory making is "a location for healing" and proceeds to think through humidity as a kind of philosophical emollient capable of revealing new, possible worlds for black bodies. Sondra Fraleigh enters the field through a different portal, that of dance phenomenology. Her article, "Get Messed Up: Intentionality, Butoh and Freedom in Plasma," presents a philosophical, first-person exploration of Butoh and subjectivity in order to enact Paul Ricouer's mission "to take phenomenology to the bloodstream." And Gretchen Jude enters the field through queer sonic studies and feminist science studies in order to flesh out a definition for the "plasmatic voice" that "functions as instances of queer assemblage stretching to reach the radically Other that constitutes ourselves-facilitating the sense of what Alaimo (2010) terms transcorporeality, an understanding of human embodiment as 'intermeshed with the more-than-human world."' On first glance, these three essays do not have much in common. And yet, upon encountering each other in the open field of Performance Philosophy, serendipitous points of commonality reveal themselves. 
Readers of these essays will find unanticipated and intersecting lines of flight through plasma, new materialism, identity, and a range of other topics. These intersections were always potentially present, but the probability of their meaningful interaction in the terrain of everyday life is quite sensible and vibrant now that the authors have met in this open field. The valences of connectivity increase when these three articles brush up with Arlander and Brannigan. Hyacinthe (a name not to be overlooked) brings hibiscus flowers to mingle with Arlander's pines and Marder's plant thinking. Fraleigh's Butoh x-rays Badiou's understanding of "dance" and unintentionally collaborates with Brannigan's nuanced critique. Is it possible that Marder's query about a performance growing like a plant finds its philosophical elaboration in the collective offerings of this journal edition? Are we witnessing a cross-pollination of different species of thought that gives rise to a philosophy whose life more closely resembles a living organism than it does an "academic discipline"?

Or, to re-phrase that as an open question: In what ways might we describe the philosophizing made visible through the collection of these specific articles in this field at this particular time in history? What does the collection say about the field itself, about its generative possibilities and its invitations to future authors? The answers to these questions become quite interesting as we acknowledge the other players. For example, consider our friends with more analytic leanings, William Teixeira, Silvio Ferraz, and David Roden. The first two work as a pair to produce "The Performance of Time (or the time of musical performance)" in which an entire history of thinking about time-both philosophically and musically_gathers around the Cello Sonata, written by Bernd Alois Zimmermann, which, according to the authors, expresses an "extended present" that becomes thinkable by focusing on the performer of the piece. Roden also takes up the issue of temporality, but his essay brings us into contact with the complex process of musical improvisation. "Promethean and Posthuman Freedom: Brassier on Improvisation and Time" rubs up against Ray Brassier's normative claims in "Unfree Improvisation," ultimately to rub against the grain of Brassier and propose "an idea of posthuman agency adapted to a hypermodern milieu of self-augmenting technological change." The parallels between these two essays are striking, given that representatives from the discipline of music studies have so far gathered in fewer numbers in our field when compared to those of performance studies, theatre, continental philosophy, and dance. Thus, in addition to considering the specifics of each article's argument, we are prompted to attune ourselves to the serendipitous overlaps between the articles, since those overlaps produce something like a harmonic relation that resonates above and throughout the field of Performance Philosophy.

One harmonious intermingling sounds off through Keti Chukhrov's essay, "Repetition as the Performative Syndrome of Dying," where the word "rhythm" detaches from its musical family and departs into the word of psychoanalytic theory. Chukhrov writes:

Rhythm is the quality that makes time uneven, anthropometric and irreversibly moving towards an end. Non-rhythmic cardinal time stands still; the rhythmized ordinal time moves unevenly, rushes and ends. Consequently, the rhythmic time is the one that exerts the peril of mortification. 
While we might easily adapt these words to fit into the arguments mobilized by Teixeira, Ferraz, and Roden, they work in Chukhrov's essay to elaborate on the specific performative dimension of playful repetition at work in the seemingly unplayful act of dying. "The strange converse effect of all this is that not only is an act of repetition the syndrome of dying, but the dimension of death and dying then automatically qualifies performing arts, becoming the attribute of the performative procedure." With these thoughts, psychoanalytic theory merges with analytic philosophies of music and constructs a kind of bridge between two distinct areas within the broader field of Performance Philosophy.

Probing this possibility of harmonics a bit more, we can return to the themes of the four biennial conferences that I referenced earlier. The first two-What is Performance Philosophy? and What Does Performance Philosophy Do?-pose questions that this editorial has partially answered. Performance Philosophy is an open field of inquiry, seeded with open questions that inquire into the nature of performance practice, philosophical inquiry, and the imbrication of these two sets of action, open to individuals from any number of established academic disciplines. In its ever-shifting totality, Performance Philosophy not only forwards claims about the productive entanglement of its two constitutive keywords; it also invites its inhabitants to investigate the ground on which they stand in order to think again about the presumed certainties of inherited academic knowledge.

In terms of this inquiry into the ground beneath out feet, two articles in edition 4.2 add to our understanding of what Performance Philosophy does. Veronika Reichl's “The Feeling of Thinking: Stories and Animations on the Experience of Reading Theory" turns a creative and critical eye on the act of reading. By presenting modified versions of interviews conducted with readers of philosophy, Reichl ensures that we stop taking reading for granted and that we see it, instead, as an active site of meaning making and emotion production. The subjects of her interviews pick up Arendt, Deleuze, Davidson, Hegel, Derrida, and Paglia and enter into an aesthetic, as well as an epistemic, event. Reichl asks of reading, "But how is it done? How is it perceived? Which aesthetic and emotional experiences take place?" These questions thus reinforce the idea that Performance Philosophy relishes not-knowing as much as it works to contribute to existing philosophical discourses. Are we so sure we know what reading is when we do it? What emotions are in play right now as you read this?

In a similarly self-reflexive playful mode of criticism, John MacCallum and Teoma Naccarato put their imaginations to work to produce "Collaboration as differentiation: Rethinking interaction intra-actively." The Derridean style erasure present in the previous sentence (i.e., self-reflexive) cites an important idea from this essay; namely, that the oft-conjured maneuver of self-reflexivity fails to advance critical inquiry. Quoting Karen Barad in their essay on this matter, we learn:

\footnotetext{
[R] eflexivity is nothing more than iterative mimesis: even in its attempts to put the investigative subject back into the picture, reflexivity does nothing more than mirror mirroring. Representation raised to the nth power does not disrupt the geometry that holds object and subject at a distance as the very condition for knowledge's possibility. Mirrors upon mirrors, reflexivity entails the same old geometrical optics of reflections. (Barad Meeting the Universe Halfway, 87)
} 
MacCallum and Naccarato are, on the one hand, concerned with the failure of self-reflexivity in the realm of interactive design. On the other hand, the critique of interaction and self-reflexivity doubles as a tacit challenge to performance Philosophers. In terms of the first point, the authors bring intra-activity into a parallel position across from inter-activity so as to highlight the "processes of differentiation by which such things are continually made and unmade." "Expanding interaction design by engaging in processes intended to bring awareness to the value systems involved in the local production of 'interaction' and 'things that interact,"' they go on to explain, "offers an opportunity to treat these values, and likewise the designers (be it engineers or choreographers or composers), as objects themselves in the design process." In terms of the second, tacit dimension of their article, MacCallum and Naccarato, like Reichl, encourage their readers to stop and look around the field of Performance Philosophy. How are we acting in this space? As we, readers/consumers and writers/producers, help to design this field through our collective activities in/on/under/above it, are we conscious of ourselves as both objects and subjects? Are we aware of the diffractive potential of each structure we place in the field?

These questions tilt toward the realm of ethics and summon the theme from the Prague conference (2017): How does Performance Philosophy Act? Among the many answers that have been put on the table, one primary answer has been this: with the body. That is, by attending to what all a body can do-how it affects as well as how it is affected-our collective understanding of thinking undergoes a radical shift and turns away from mind-centered, idealist conjectures put forward over the last two millennia by science and philosophy alike. Sophie Doutreligne and Christel Stalpaert's "Performing with the Masquerade: Towards a Corporeal Reconstitution of Sophie Taeuber's Dada Performances" shows us, however, that a lot of work is required to reconstitute the bodies of historical subjects, especially when the materiality and movements of those bodies have been obscured by patriarchal and scopophilic regimes. In this particular case, it is the body of Sophie Taeuber that has been frozen within the Dada image archive. To reconstitute Taeuber's body and movements, the authors draw upon (the somewhat unlikely pairing of) Bruno Latour and Luce Irigaray in order to demonstrate how, through performance, the Dada artist baffled the rigid paradigms of masculinity and femininity structuring the realms of the visible and sayable in her time.

Concerned with an altogether different historical narrative, Georg Doecker analyzes the various iterations of the tale of "Libertatia," an ostensibly fictional pirate colony that's influence on modern literature is without question. The goal here, as in the case of Doutreligne and Stalpaert, is to scrutinize the way bodies act. In particular, his essay, "The Curiosity for Panic. On the Stories of Libertatia and Self-Organisation in Anarchism, Cybernetics, and Performance," is interested in the mechanics of self-organization that support anarchist communities. Finding that selforganization-at least in the tales of Libertatia-thrives on the entropic counterforces of selfdisorganization, Doecker's essay prompts readers to re-evaluate the seeming "failures" of groups like Occupy Wall Street in such a way as to see in those groups' dissolution a salutary form of regeneration and transformation. 
And with this discussion of self-organizing groups, we almost return to where we started, with a conversation about the field of Performance Philosophy. First, however, there are two more contributions to mention. First: Narjis Mirza's "Ta'wil: in Practices of Light." Having touched on what Performance Philosophy is, what it does, and how it acts, it is perhaps best to discuss this article in light of the upcoming, fourth biennial conference theme, "How does Performance Philosophy intervene?" Specifically, we can inquire into the ways that artists and scholars challenge and contest Western paradigms of thought while continuing to pursue philosophical lines of questioning. Mirza brings her own artistic practice to bear on this conversation, which, in turn, finds its inspiration in the Islamic philosophy of Mulla Sadra, particularly in his philosophical ruminations on light. Inspired by both the school of Ibn Arabi and Suhrawardi's Illuminationism, Mulla Sadra incorporates centuries of Islamic thought into his philosophical system. Mirza's light installations draw from this system and offer spectators a medium through which to embark on a spiritual journey. The intervention of this art and this essay does not only arise from its Eastern trajectory of thought-thereby forcing us (me?) to re-evaluate the givenness of our (my?) Western lineagebut also comes in the artful way that Mirza links Sadra's thought to Bergson who was himself influenced by the mystical branches of Islamic philosophy. Ultimately, Mirza's stance does not place her on the outskirts of the field we call Performance Philosophy but, instead, points the way to an as-yet under-explored territory of philosophical thoughts, there where Western and Eastern paradigms entangle.

Neither is the contribution to the [MARGINS] section of the journal truly on the margins since, after all, can an open field have margins? How does the center/periphery binary transform when "center" and "periphery" lose their geographical certainties? The collective Generative Constraints does not ask this question through their piece, "Break Up Variations: An Annotated Score," but they do ask a question that leads to a similar place: Might a "break up" become the most intimate dimension of any relationship?

\section{What we've got in common is this break up. That is our relationship, that we are broken up. We will be broken up forever and that is the most romantic thing there is. We'll never always be together. We'll always be always apart.}

If so, then the binary (constraint) of together/broken up gives way to a (generative) series: together-broken up-somehow more together. What appears as decoupling leads to metastasis within the relationship, a growth the size and shape of which cannot be easily foreseen. Thus: Brexit will metastasize the relationship of "Europe" (and "Great Britain"). A performance score will metastasize the internal relationships of the performance act as it works to become the index of the latter. A group of artists and thinkers agrees to part ways, thereby infusing the agreement to separate with a life that keeps on living.

Now, then, back to the beginning. As Colby and Schultis implicitly ask, what all is going on in this field, and what can we expect in the near future? If edition 4.2 is indicative of the openness of Performance Philosophy, in the ways discussed throughout this editorial, then we can expect a broadening of views on what precisely "performance" and "philosophy" are, how they interact, why 
we should care to attend to their interaction, and the forms of language mobilized to discuss these interactions (break-ups included). That is, we do not glimpse the slow growth of vertical structures upon this open field but, rather, a horizontal flow of energies produced by moving bodies and motile thoughts. The purpose of these energies may be as yet unclear, but their vibrancy and capacity to stimulate discussion cannot be denied.

\section{Biography}

Will Daddario is the author of Baroque, Venice, Theatre, Philosophy (Palgrave 2017), and co-editor of two anthologies: Adorno and Performance (with Karoline Gritzner, 2014) and Manifesto Now! Instructions for Performance, Philosophy, Politics (with Laura Cull Ó Maoilearca, 2013). He is co-editor (with Cull Ó Maoilearca and Alice Lagaay) of the Performance Philosophy Book Series (with Palgrave), and a founding member of the international research network Performance Philosophy. He currently lives in Asheville, North Carolina where he produces (with Joanne Zerdy) the "To Grieve Podcast" as part of his work with Inviting Abundance.

(c) 2019 Will Daddario 